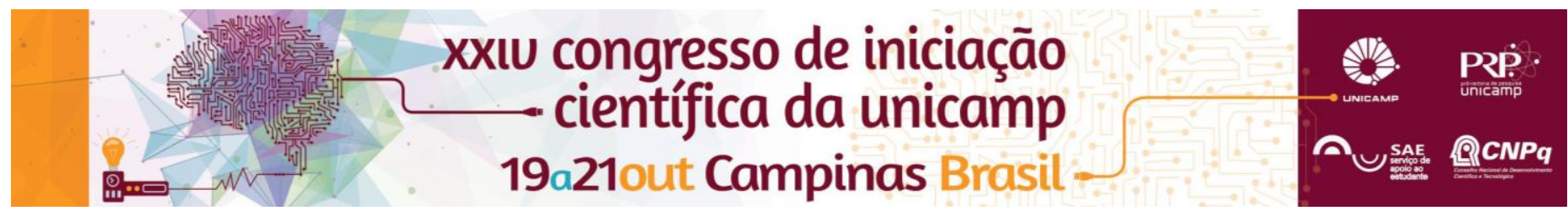

\title{
The work with animals' images proposed by LUME Teatro to the practical study of the impulses.
}

\author{
Stefanie G. G. Tavares da Silva*, Eduardo Okamoto.
}

\begin{abstract}
A practical-theoretical study of the relations between the methodology developed by LUME Teatro of animals' images incorporation with the concept of "impulse" as formulated for the polish director Jerzy Grotowski. Thereunto, we have a study group (7 students graduating at Performing Arts) that works practically LUME's methodology under the guide of LUME's members. Furthermore, it's realized a bibliographic investigation of Grotowski's work, trying to delimitate the concept of "impulse"
\end{abstract}

\section{Key words:}

Grotowsk, Impulse, Animals' images.

\section{Introduction}

This project starts from the hypothesis that the work with animal' images proposed by LUME can be relate to one of the fundamental elements of the action's study according to Grotowski: impulses.

In our first meetings we worked on exercises developed/incorporated by LUME which we believe to be related to the first phase of this research: to understand where comes the body impulses comes from. Later, we began working with the incorporation of animal images. At this stage we worked from the live observation of animals, then back to the room the we searched for the bodies observed. Always aiming to "equivalence", not "be" the animal, but "feel" the animal. The fundamental goals are to understand how the animal's physical composition determines a type of action, highlights specific impulse qualities, and how the impulses help the body to answer quickly in form of action.

For Grotowski training was to eliminate any body's resistance to impulses development process. As result they obtained the decrease in time lapse between inner impulse and outer impulse (external action)

\section{Results and Discussion}

In the study of impulses (such as naturally / instinctively) we deepened perception of the muscular way taken by them, necessary changes in the body to unlock them. We've realized that when an impulse occurs in the abdomen, the whole body reacts at the smallest places; It is not the reason that works, the body just does. We've worked on the possibility of building an impulse, I don't believe it's possible; or pre-establish what will the body do to improve the impulse; but we think it's possible to let the body in a position to have impulses, preparing it to generate it. In our studies we understood that to Grotowski, impulses originated from practice, and the actors become more aware of the process as they work on the exercises. The concept of impulse that the author argues in his work, undoubtedly is presented at the work with animals, but here there is something else: the vitality center. This is the "expression generator", is where the animal guides, a central feature of its motions. There isn't much information about it in Grotowski's writtings.

The exercises that we worked on, permitted, as well as research the above-mentioned aspects, the study of many other actor's qualities such as attention, intention, eliminating tensions, presence and voice, which were developed more vertically in the scene resulted of this process.

\section{Conclusions}

We believe that definitely all kinds of impulse rises from the abdomen (as said by Grotowski and LUME), even if it has flow rate thru other part of the body. If it's an action, starts there. When we connect with this part of the body, we perform what Grotowski called "total act", it means, something that the actor performs with his whole being, not determined by logical thinking. in its meaning, we can affirm according to our experience that the work of animals' images incorporation was essential for us to turn down in the attempt to guide an action from a rational thinking. When found in our body the fundamental equivalence ("the action's heart"), and followed rigidly, we can find the center of impulses, from where starts its actions, thereby determining a "form" to act, a "personality". For the group, mimic the animal's way to look is critical to the process. We awakened to an easy quick response to situations, which means -we believewe reduced the time between action-reaction. We trust after this research that essentially, the difference between the impulse to Grotowski and LUME is that: for the first, the impulse pre-exists, and only can/must be unlocked; for the second, the impulse is something that can be created using devices.

\section{Acknowledgement}

I thank FAPESP for encouraging new researchers and arts, and also for the funding.

Thanks to the always dedicated and patient Eduardo Okamoto, and to the actors Jesser de Souza and Raquel S.Hirson, from LUME Teatro, for sharing with me part of theys knowledgement.

The Arts Institute, all employees and Mesters with whom l've learned and are essential part of my formation.

My family, for the support and care with me always; and Marcelo, for all the love to me dedicated.

The animals that will always be with us with in memory.

Essentially Jerzy Grotowski, for the dedication of a lifetime to a sensitive work that so much awakened me. 